\title{
Cidade e interação: o papel do espaço urbano na organização social
}

\section{City and interaction: the role of space in social organization}

Vinicius M. Netto ${ }^{[a]}$, João Meirelles ${ }^{[b]}$, Fabiano L. Ribeiro ${ }^{[c, d]}$

\author{
[a] Universidade Federal Fluminense (UFF), Niterói, RJ, Brasil \\ ${ }^{[b]}$ École Polytechnique Fédérale de Lausanne, Laboratory on Human-Environment Relations in Urban Systems, Lausanne, Suisse \\ [c] Universidade Federal de Lavras (UFLA), Lavras, MG, Brasil \\ [d] University of London, London, United Kingdom
}

\section{Resumo}

Como ações pessoais, aparentemente caóticas, podem gerar os imensos sistemas de interações em que vivemos? Neste artigo, buscamos responder a esta pergunta sugerindo que há um papel para as cidades, na forma de coordenar nossas ações. Investigamos esse processo explorando um conceito particular: a "entropia" ou como sistemas lidam com a incerteza e imprevisibilidade na transição de ações individuais para sistemas de ação. Examinando as condições de (i) as ações como dependentes da informação em seu ambiente e de (ii) a cidade como ambiente de informação, propomos que (iii) a cidade produz diferenças na probabilidade de que certas interações venham a ser realizadas. Investigamos este processo através de simulações de diferentes cenários, de modo a identificar o espaço como uma condição necessária, mas não suficiente, para reduzir entropia social. Finalmente, sugerimos que os estados e flutuações da entropia são uma parte vital da reprodução social, e revelam profundas conexões entre sistemas sociais, informacionais e espaciais.

Palavras-chave: Cidade. Interação. Informação. Entropia.

\section{Abstract}

How can seemingly chaotic personal acts create the coherent systems of interaction that surround us? In this paper, we attempt to answer this key question by suggesting the role for cities on how we coordinate seemingly chaotic decisions. We look into these elementary processes exploring a particular concept: "social entropy", or how social systems deal with uncertainty and unpredictability in the transition from individual actions to systems of interaction. We examine the following conditions: (i) actions rely on informational differences latent in their environments, (ii) the city itself is an information environment to actions, and we propose that (iii) space becomes a form of creating differences in the probabilities of interaction. We investigate this process through simulations of distinct material scenarios to find that space is a necessary but not sufficient condition for the reduction of entropy. Finally, we suggest that states and fluctuations of entropy are a vital part of social reproduction, and reveal a deep connection between social, informational and spatial systems.

Keywords: City. Interaction. Information. Entropy.

VMN é urbanista, doutor, e-mail: vmnetto@id.uff.br

JM é engenheiro ambiental, mestre, e-mail: joao.meirelles@epfl.ch

FLR é físico estatístico, doutor, e-mail: fribeiro@dfi.ufla.br 


\section{Introdução: desafios na reprodução social}

Entre as questões que habitam a "imaginação sociológica" (Mills, 1959), uma é particularmente aguda: como relacionamos nossas ações pessoais em interações capazes de criar uma sociedade? Como as ações cotidianas podem gerar um sistema coerente de tamanhas proporções? Estas perguntas se mostram mais cruciais se pensarmos nos desafios enfrentados por sociedades contemporâneas, como a crescente profusão de informação e comunicação. Por exemplo, a capacidade de processamento computacional dobra a cada dezoito meses, mas o volume de dados dobra a cada doze meses (Hidalgo, 2015; Helbing, 2016), tornando impossível processar todas as informações disponíveis no longo prazo.

Curiosamente, o sociólogo Niklas Luhmann (1995) vê esse excedente de informação trazendo mais possibilidades de ação - implicando em um desafio de seleção que parece mais e mais imposto em nossa experiência. De acordo com Luhmann, uma questão enfrentada por sistemas sociais é "entre as possibilidades de informação e de comunicação, quais serão realizadas?" Considerando que temos mais possibilidades do que podemos conhecer e processar, a própria maneira como construímos nossas interações depende desta seleção. Para todos os efeitos, mais informação e possibilidades significa menos certeza e menos previsibilidade.

Esta complexidade crescente tem um nome: entropia, uma medida da probabilidade da ocorrência de eventos e da nossa habilidade em reconhecer ordem face à imprevisibilidade e incerteza. Na verdade, sistemas sociais lidam com entropia o tempo todo. Nossas ações individuais são atravessadas por incertezas - desde as escolhas diárias do que vamos fazer até o modo como nossas escolhas vão se desdobrar, quando nossas ações se ligarem às ações de outras pessoas. Mas entender esse processo requer uma perspectiva um pouco diferente - uma perspectiva focada nas condições nas quais nossas escolhas são feitas: as condições que precisam estar presentes para que as possibilidades de ação sejam conhecidas. Precisamos de meios para conhecer essas possibilidades e para coordenar nossas ações coletivamente. Naturalmente, há diversas formas para obtermos informação e para cooperarmos: a linguagem que compartilhamos, meios de comunicação como telefones e redes digitais, leis e regras de conduta e mesmo a moeda e valores mediando sistemas de troca - itens que o sociólogo Talcott Parsons (1972) chamava steering media: "meios de direcionamento" ou guias para a coordenação da ação.

Gostaríamos de examinar neste artigo um meio de coordenação da ação ignorado por Parsons e pela teoria social. Sugerimos que, entre todos os sistemas e tecnologias criados para nos dar informações sobre o que está disponível no mundo social, há um sistema silencioso, historicamente fundamental, mas amplamente ignorado talvez por estar constantemente conosco: a cidade. Vamos argumentar que possibilidades de ação são apresentadas a nós pelo nosso próprio ambiente, que esse ambiente é profundamente espacial e que toma a forma de cidades. Discutiremos como este seria o caso: como as cidades desempenham um papel na forma como nossas ações individuais aparentemente caóticas se tornam sistemas de interação.

Essencialmente, propomos acompanhar os momentos de passagem das possibilidades de ação em torno das nossas decisões para a realização das nossas ações na vida cotidiana. Sugerimos que a análise do papel das cidades nessas passagens pode esclarecer a constante ordenação e desordenação da ação, ajudando a explicar a reprodução de uma sociedade mais completamente. Argumentaremos que os espaços da cidade têm o efeito de reduzir a incerteza e a imprevisibilidade na transição de ações individuais para os sistemas de interação. Agentes sociais se envolveriam inconscientemente nos processos de organização sempre que realizam ações na cidade. Dado que a organização das interações em nossas vidas diárias transcende contextos locais, indo para além da nossa observação direta, traremos simulações in silico para esclarecer o papel das cidades nessa trama. Estes experimentos computacionais visam explorar o modo como, cada vez que atuamos na cidade, participamos da re/criação constante de sistemas de interação.

Uma vez que o tema do artigo está posto, a seção 2 discute "entropia", concentrando-se na teoria da informação e na teoria social, a fim de chegar a uma instância pouco explorada da entropia na interação. A seção 3 estabelece um papel para cidades como ambiente de informação, enquanto a seção 4 trata da cidade como um "sistema de referência" para as ações e como elas se conectam. A seção 5 traz a hipótese de como a redução da entropia mediada pela cidade se torna parte essencial da organização social. Examinamos esse processo na seção 6, propondo um 
modelo (agent based model, ABM) capaz de avaliar o papel de fatores sociais e espaciais, tais como agentes capazes de ler informações no espaço. Na seção final, discutimos o que nossa teoria e modelo dizem sobre o papel das cidades na interação social.

\section{O que é entropia social?}

O conceito de entropia, um termo derivado da palavra grega tropos, "transformação", tem origem na Física, especificamente a segunda lei da termodinâmica, que descreve o processo irreversível de dissipação da energia. Ele foi avançado por Ludwig Boltzmann (2015) em 1877, ao abordar processos de desequilíbrio, ligando as propriedades macroscópicas de um sistema à sua desordem microscópica. A teoria diz que há muito mais estados desordenados possíveis do que estados ordenados, de modo que os sistemas tendem a se mover em direção à desordem. No entanto, a entropia não é uma propriedade exclusiva de sistemas físicos. A noção foi traduzida para questões externas à física por Shannon (1948), no problema da transmissão da informação. A partir daí, uma série de teóricos passaram a ver entropia também em sociedades. Eles têm explorado a medida de informação de Shannon desde o final da década de 1960 em um campo conhecido como "Teoria da Entropia Social" (e.g. Buckley, 1967; McFarland, 1969). Charvát (1972) e Charvát et al. (1973) propuseram ideias como "entropia semântica" na tomada de decisões e "entropia de comportamento" para examinar a homogeneidade e dependência entre sistemas, enquanto Horan (1975) desenvolveu uma medida de redução de incerteza. A entropia foi essencialmente vista como o oposto da informação - algo que deve ser controlado pelo sistema social (Klapp, 1975).

Alguns desses argumentos são particularmente interessantes para a nossa abordagem. Galtung (1975) analisou entropia a níveis micro e macroscópicos, usando dois tipos básicos: a "entropia do ator" e a "entropia da interação". Forças moveriam um sistema social como em um pêndulo, oscilando entre estados de baixa e alta entropia. Normas, funções e outras estruturas do sistema social seriam restrições internas sobre seu comportamento, capazes de mantê-lo abaixo da máxima entropia. Outras abordagens lidam com sociedades como coleções de agentes que interagem no espaço-tempo dentro de fronteiras geográficas
(Miller, 1978). Bailey (2006) também relacionou entropia a medidas do tamanho de uma cidade, da população e do território. No entanto, tais concepções têm uma espacialidade frágil. Nelas, o espaço tende a ser um pano de fundo, não uma parte do problema da organização ou de sua resolução no tempo. Por sua vez, não encontramos muito apoio nas disciplinas espaciais: salvo exceções como Batty (2013), elas têm ignorado as condições de produção da ação social e, portanto, o papel das cidades nessa produção. A fim de incluir cidades sistemicamente, sugerimos abordar o problema da interação voltando à nossa questão inicial: como ações individuais aparentemente imprevisíveis podem levar a sistemas coerentes de interações?

Encontramos uma maneira de responder a esta pergunta em Luhmann (1995): sociedades produzem mais possibilidades de ação do que podem converter em ações concretas, o que por sua vez impõe a necessidade da seleção. Luhmann entende sociedades como subsistemas interligados onde eventos são formados via comunicação. Os elementos estruturais que compõem esses subsistemas são frágeis: os momentos de seleção e conexão entre nossas ações. A continuidade de um sistema social requer a capacidade de produzir essas conexões. Mas em sociedades com uma quantidade crescente de agentes e informações, o número de interações possíveis cresce enormemente. Temos o aumento de um tipo de complexidade que Luhmann chama "não estruturada": uma complexidade entrópica. Esse tipo de complexidade pode levar a perdas semânticas e organizacionais. Este horizonte de riscos nos ajuda a perceber os desafios que sociedades enfrentam o tempo todo.

Para entender melhor esse cenário social propenso à entropia, voltemos à definição pioneira de Shannon (1948). Shannon definiu entropia no contexto de comunicação. 0 problema fundamental da comunicação é o de reproduzir em um ponto uma mensagem produzida em outro ponto, exata ou aproximadamente. As mensagens têm significados, relacionados com certas entidades físicas ou conceituais. Se o número de mensagens em um conjunto é finito, a entropia é medida pela distribuição das probabilidades de que certa mensagem ou signo venha a ocorrer.

Um exemplo vai ajudar a esclarecer como a entropia da comunicação se reduz, pelo uso da probabilidade de frequência de signos. Na Figura 1, a linha 1 mostra letras independentes, com a mesma probabilidade 


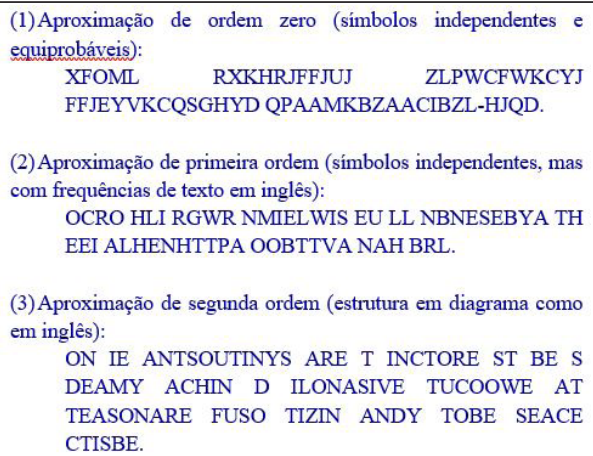

(3)Aproximação de segunda ordem (estrutura em diagrama como em inglês):

ON IE ANTSOUTINYS ARE T INCTORE ST BE S DEAMY ACHIN D ILONASIVE TUCOOWE AT TEASONARE FUSO TIZIN ANDY TOBE SEACE CTISBE.

(4) Aproximação de terceira ordem (estrutura em trigrama como em inglês):

IN NO IST LAT WHEY CRATICT FROURE BIRS GROCID PONDENOME OF DEMONSTURES OF THE REPTAGIN IS REGOACTIONA OF CRE.

(5)Aproximação de palavras de primeira ordem. Em vez de continuar com estruturas em tetragrama, ..., $n$-grama, é melhor a partir daqui usar unidades de palavras. Aqui, as palavras são escolhidas de forma independente, mas com suas frequências apropriadas:

REPRESENTING AND SPEEDILY IS AN GOOD APT OR COME CAN DIFFERENT NATURAL HERE HE THE A IN CAME THE TO OF TO EXPERT GRAY COME TO FURNISHES THE LINE MESSAGE HAD BE THESE.

(6)Aproximação de palavras de segunda ordem. As probabilidades de transição de palavras estão corretas, mas nenhuma estrutura adicional foi adicionada:

THE HEAD AND IN FRONTAL ATTACK ON AN ENGLISH WRITER THAT THE CHARACTER OF THIS POINT IS THEREFORE ANOTHER METHOD FOR THE LETTERS THAT THE TIME OF WHO EVER TOLD THE PROBLEM FOR AN UNEXPECTED.

Figura 1 - Redução de entropia na construção da linguagem Fonte: Shannon (1948).

de ocorrer. Em uma primeira ordem de aproximação (linha 2), as letras seguem independentes umas das outras, mas têm a probabilidade de aparecer em frases que elas encontram na língua inglesa. Na linha 3, temos a adição da frequência em que letras aparecem em pares. Na terceira aproximação (linha 4), as letras são ordenadas de acordo com a probabilidade de estarem associadas em trios em inglês. Já a linha 5 mostra palavras independentes, mas com a mesma probabilidade de aparecerem em frases reais. Finalmente, a linha 6 mostra o que acontece com uma frase com palavras escolhidas aleatoriamente, mas atendendo a mesma probabilidade de serem seguidas por palavras específicas na língua real. 0 que esse experimento mostra é que, mesmo sem usarmos os significados das palavras, chegamos a uma mensagem quase inteligível simplesmente a partir das probabilidades de estas se sucederem. As diferenças na frequência das letras e palavras produzem diferenças na probabilidade de sua ocorrência. Na prática, isto significa que os componentes de mensagens se tornam mais previsíveis e inteligíveis. A redução da entropia permite que nos comuniquemos.

0 que isso tem a ver com entropia social? Vimos que sociedades são sistemas de ação e comunicação. As ações das pessoas são mediadas por informação: elas têm significados, que se iniciam na orientação pessoal (Weber, 1978), e estão nos seus conteúdos informacionais (Luhmann, 1995) e conteúdos práticos (Wittgenstein, 2001). Como as diferenças entre signos vistas por Shannon, os significados diferenciam as coisas: eles produzem diferença informacional. Reconhecemos coisas e ações através dessas diferenças - por exemplo, nas expressões ou nas tarefas que fazemos. Em princípio, quanto maior a diversidade de orientações, mais difícil será prever a próxima ação de alguém. Mas há algo a mais. Um estado de alta entropia envolve as possibilidades da ação — ou seja, as ações em estado potencial, antes de ocorrer, quando temos diferentes opções à frente.

Combinando os insights de Shannon e Luhmann, vemos que o problema informacional que os agentes enfrentam diariamente, mesmo que inconscientemente, está em lidar com a seleção. Experimentamos entropia sempre que lidamos com opções, incerteza, decisões, muita informação ou situações imprevisíveis - mas raramente nos damos conta disso. Não podemos ver ou tocar "entropia". A entropia é um fenômeno que está além da observação. Não estamos acostumados a pensar sobre os desafios que enfrentamos quando fazemos escolhas ou buscamos realizar nossas intenções. Entretanto, a questão chave aqui é como o campo de possibilidades das nossas ações envolve seu ambiente - um ambiente na verdade espacial. Precisamos entender como as cidades fazem parte do processo de seleção que constitui a interação. E o primeiro passo é compreender o espaço da cidade como informação.

\section{A cidade como ambiente de informação}

Luhmann mostra que sistemas sociais estão imersos em produção semântica: significados se tornam seu ambiente. Vamos desenvolver essa ideia explorando o espaço urbano como parte desse "ambiente de informação". Buscamos a ponte entre a cognição de agentes capazes de produzir e extrair informação de seu contexto, e a ação de agentes 
capazes de usar essa informação no seu cotidiano. O objetivo é vermos como a informação se torna parte das interações. Para tanto, precisamos firmar nossa abordagem em um entendimento de (1) a cognição como sendo ligada ao seu ambiente; (2) a cognição como sendo importante para a ação; e (3) o espaço urbano como ambiente de informação capaz de mediar ações. Encontramos forte suporte para esses passos. De Vygotsky (1978) e Rapoport (1982) a Wilson (2002) e Haken \& Portugali (2015), propriedades cognitivas do espaço e propriedades espaciais da cognição vêm sendo identificadas.

(1) A cognição é situada. Nossa atividade cognitiva ocorre em um ambiente real, que envolve nossa percepção. Processos cognitivos são moldados em coordenação com recursos externos à mente (Vygotsky, 1978). Quando atuamos, informação perceptual é capturada de forma a afetar nossas ações. 0 modo como mergulhamos em atividade cognitiva está ligado à nossa interação contínua com o ambiente (Wilson, 2002). Teorias da "mente estendida" (extended mind) afirmam um fluxo causal à medida que a mente usa recursos do ambiente $\mathrm{e}$ vice-versa, uma interação bidirecional em um sistema contínuo, mente-ambiente (Clark \& Chalmers, 1998). A ordem e a sistematicidade na cognição e ação humana decorrem em parte da estabilidade do nosso ambiente (Michaelian \& Sutton, 2013);

(2) Carregamos o ambiente construído de informação. Certos processos cognitivos disparam associações com elementos do ambiente através da incorporação de informações (Passini, 1992). Essas informações são classificadas em categorias compartilháveis (Rosch, 1978). Processos de agregação conectam itens de informação através de similaridades entre aspectos físicos do ambiente, ou através de relações entre seus significados (Kintsch, 1970). Elementos do ambiente (digamos, edifícios ou lugares) são interpretados através de significados socialmente compartilhados (Neisser, 1994). Elementos visíveis de uma cidade transmitem quantidades diferentes de informação (Haken \& Portugali, 2015). Pequenos detalhes (como a entrada de um edifício) podem ser relacionados a ordens superiores de informação e formação espaciais (como a uma rua ou área de uma cidade). Isso quer dizer que a informação espacial pode ser arranjada em níveis hierárquicos em nossas mentes. A probabilidade de um edifício ou lugar evocar uma representação mental compartilhada pelas pessoas é reforçada pela sua aparência física e identidade visual, assim como pela sua visibilidade e localização no ambiente urbano, e pela informação social que associamos a ele, via atividades lá realizadas (Faria \& Krafta, 2003; Portugali, 2011);

(3) A informação espacial reduz nosso trabalho cognitivo. Lidamos com o ambiente e suas características também via memória. Entretanto, a memória de curto prazo é limitada na sua capacidade de processar informação (Haken \& Portugali, 2015). Portanto, em vez de mantermos todos os detalhes relevantes sobre atividades em nossa memória de curto prazo, nós capturamos estes detalhes a partir do próprio ambiente como fonte de informação e extensão de memória (Kirsh \& Maglio, 1994). A informação ambiental é uma forma de reduzir o esforço de memorização. Outros recursos como imagens mentais e sonoras são capazes de preservar propriedades espaciais e semânticas do mundo externo (Kosslyn, 1994). Este aparato externo a nossas mentes aliviaria o que Wilson (2002) chama de "gargalo de representação": os limites de nossa capacidade de memória interna. Esses limites nos levariam a estender nossos recursos mnemônicos ao ambiente;

(4) A cognição é pressionada pelo tempo. Nossas atividades diárias exigem capacidade de resposta. Mais capacidade cognitiva pode ser construída a partir de camadas de interação em tempo real com o contexto espacial. Criamos modelos mentais do ambiente a partir do qual podemos criar planos de ação. A pressão do tempo exige decisões espaciais (Brooks, 1999; Clark, 1997; Pfeifer \& Scheier, 1999);

(5) A informação espacial serve a ação. Agentes reconhecem instruções sobre eventos encontrados no ambiente espacial de forma indexicada (Glenberg \& Robertson, 1999). Manipulamos o ambiente espacial como uma forma de lidar com nossos problemas práticos. Nossa cognição inclui mecanismos adaptativos que servem a nossas atividades (Franklin, 1995). Nossa memória cognitiva evoluiu a serviço da percepção e da ação em um ambiente tridimensional (Wilson, 2002). A cognição serve à ação por meio de estratégias flexíveis, nas quais a informação é armazenada 
para uso futuro. Novas utilizações não precisam ser desencadeadas por observação direta do ambiente urbano (Gibson, 1979). Esta é uma estratégia cognitiva adaptativa. 0 fato que humanos codificam o mundo físico usando modelos mentais espacialmente e semanticamente estruturados oferece uma enorme vantagem na prática humana.

Este recurso cognitivo inclui propriedades espaciais que nos permitem fazer inferências - por exemplo, imaginar a rua mais provável para encontrar certa atividade. Modelos mentais são baseados em uma "modelagem do mundo físico" (Lakoff \& Johnson, 1999). Outros trabalhos amarram semântica com esquemas imagéticos incorporando o mundo físico como forma de codificar relações entre eventos. Ao perceber algo, nós percebemos não só a forma observada, mas também a informação potencial associada (Haken \& Portugali, 2015). Esta propriedade é crucial para nosso uso do espaço urbano para atuarmos diariamente.

Esses estudos indicam que nossas ações codificam o espaço com informações, e esse espaço informacional tem o papel de aliviar nossas memórias. Somos capazes de recuperar informações do arranjo semântico que é a cidade - e fazemos isso antes e durante nossas ações. Essa camada semântica é armazenada em lugares de atividade, assim como nas relações espaciais entre lugares, e está atrelada a heterogeneidades, incluindo de acessibilidade e centralidade (Faria \& Krafta, 2003). Essas camadas de informação espacial podem ser evocadas a partir de nossas memórias, e usadas quando precisamos fazer inferências digamos, onde encontrar certa atividade ou agente. No entanto, o que as teorias da cognição situada ainda não reconhecem é como esse espaço informacional faz parte da interação. É isso que queremos entender.

\section{A cidade como sistema de referência}

Propomos explorar o papel informacional do espaço urbano começando com as comunicações que constroem conexões entre ações e situações sociais em que participamos. Sabemos que o espaço urbano é produzido para expressar essas situações. Mas as teorias de cognição situada sugerem muito mais: o espaço e os lugares de atividade são diferenciados. Esta diferenciação está associada com a própria forma do espaço urbano, em pelo menos três níveis: (i) em termos visuais, nas formas tridimensionais reconhecíveis (Haken \& Portugali, 2015); (ii) em suas propriedades de extensão e configuração, tais como a distância e acessibilidade dentro de uma cidade (Hillier, 1996); e (iii) nos seus conteúdos semânticos, associados com edifícios e lugares de atividade (Faria \& Krafta, 2003; Portugali, 2011) (Figura 2).

Como este espaço informacional pode se tornar parte da ação? Há uma notável falta de pesquisas sobre este problema - mas o que os achados visitados

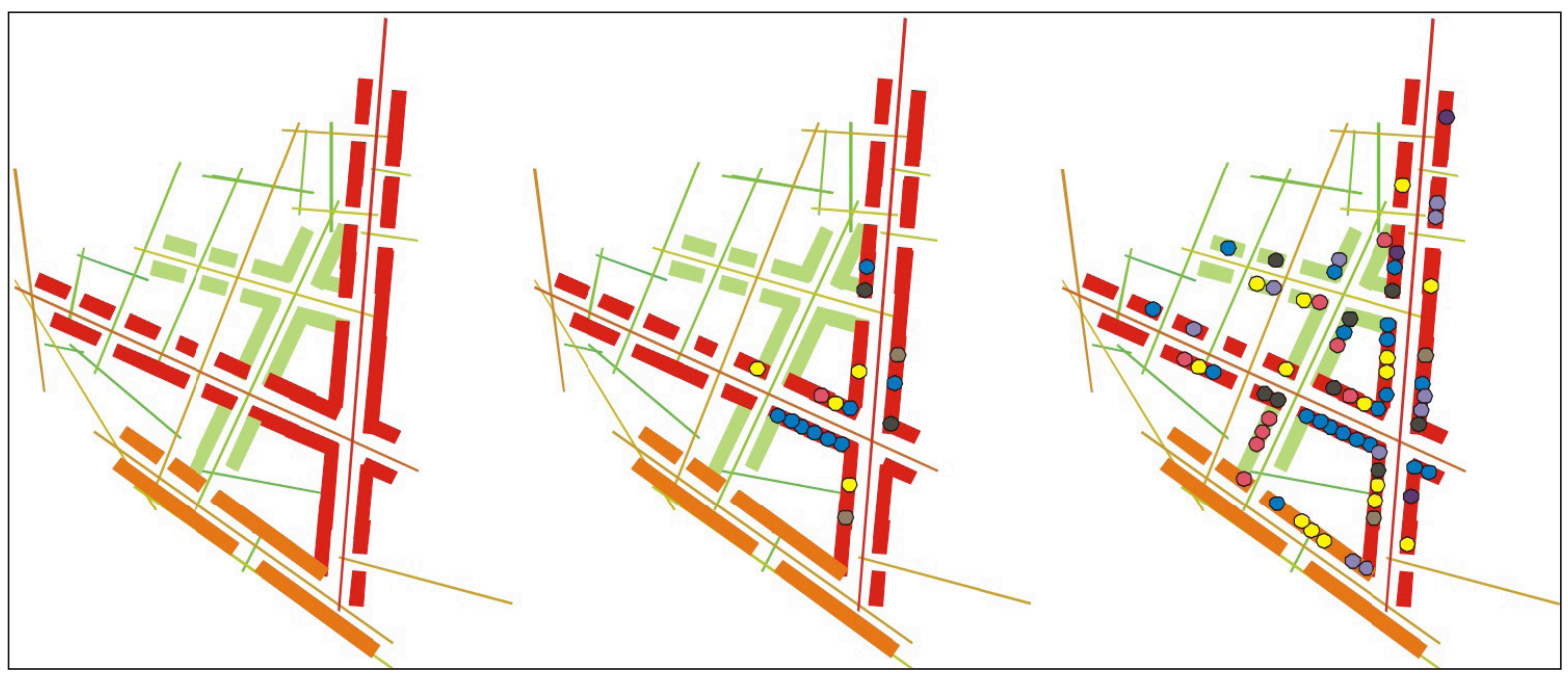

Figura 2 - Espaço diferencial: como um código de instruções para a aç̃ão coletiva, o espaço urbano encontra diferenciação física, enquanto hierarquias de acessibilidade e distribuição de forma construída (à esquerda), e semântica, por meio de ações realizadas em edifícios e lugares (centro e direita) Fonte: Autores. 
acima nos permitem dizer é que, em primeiro lugar, lemos significados nos espaços arquitetônicos e urbanos potencialmente associáveis com nossas ações. Captamos informações úteis sobre a atividade realizada em certo lugar não só por características visuais, mas também por observar e inferir que as pessoas fazem lá (veja Goffman, 1956; Garfinkel, 1967). 0 espaço não só representa a atividade social: ele é atuado - portanto, carregado de significados relacionados a nossas atuações, e pode adquirir um nível de definição semelhante a categorias da ação. Esta é a dimensão semântica do espaço: o espaço "significa" tanto quanto nossas ações, porque é semantizado por nossas ações (Netto, 2008, 2017). Esta informação "atuada" é muito importante. A ação passa a estar relacionada com uma localização temporal e espacial específica. Quando materializada no espaço, uma ação passa a ocupar uma posição única na realidade ${ }^{1}$.

Segundo, esses lugares nos permitem acessar interlocutores. Na vida real, as pessoas percebem as diferenças entre lugares. São essas diferenças que nos ajudam a fazer seleções de onde e com quem atuar. Quando saímos de casa buscando um serviço, recorremos à memória de localizações criadas em experiências passadas. Quando não sabemos onde encontrar esses serviços ou conhecemos aquela área, fazemos inferências sobre onde encontrá-los a partir de ruas mais acessíveis ou áreas mais densas, que associamos a maior chance de encontrar a atividade. Reconhecer diferenças ou padrões espaciais nos permite inferir localizações úteis. Além de outras fontes de informação, tais como pessoas ou recursos digitais, aprendemos sobre a existência dessas atividades pela própria cidade.

Terceiro, os lugares são meios de conexão social: ao acessar um lugar, podemos produzir ligações com determinadas pessoas e atividades durante um período de tempo. Essas ligações espaciais nos permitem conectar nossas ações em sistemas. Na prática, os lugares urbanos atraem diferentes ações e as amarram momentaneamente. Estes fluxos de ações convergentes acontecem o tempo todo - quando as pessoas vão ao trabalho, buscam serviços ou socializam, muitas vezes sem conhecimento prévio dos lugares e agentes que desejam encontrar (Figura 3). 0 espaço urbano

\footnotetext{
${ }^{1}$ Veja Heidegger (1962, p. 136) sobre a "multiplicidade de lugares" e "posições possíveis".
}

se torna um "sistema de referência" para nossa ação (Netto, 2008, 2017).

\section{Entropia e organização social}

Para se tornar parte das ações, lugares devem ser conhecidos ou imaginados, e escolhidos para materializar essas conexões. Mas se as cidades contribuem de alguma forma para facilitar essas conexões, não seria razoável pensar que certas formações urbanas poderiam facilitar conexões mais do que outras? Podemos começar a identificar essas condições espaciais através de um cenário contrafatual. Imaginemos uma formação urbana totalmente caótica, sem concentrações reconhecíveis ou caminhos visíveis. Elementos visuais não transmitiriam informações; diferenças espaciais não gerariam estruturas reconhecíveis. As referências a atividades de interesse teriam de depender apenas da nossa capacidade de memorizar essa heterogeneidade. Inferências sobre lugares mais prováveis para se encontrar certas atividades se tornariam muito difíceis. Em um mundo de espaços completamente desestruturados, as ações enfrentariam ruído, falta de informação e uma entropia sem fim.

Entretanto, nossa experiência diária nega que as cidades sejam lugares completamente caóticos. Além

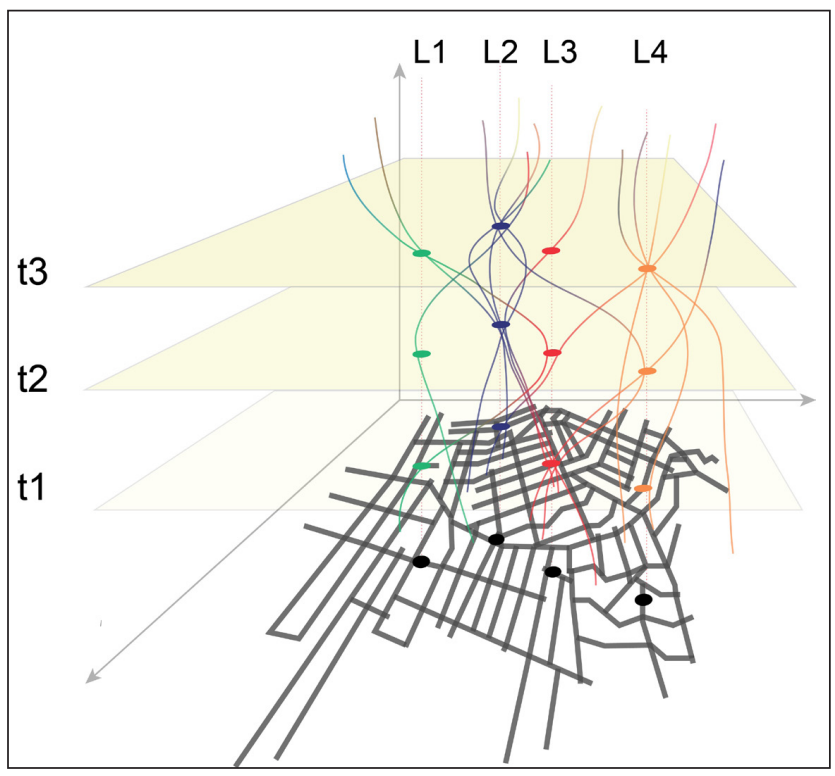

Figura 3 - Como um sistema de referência, o espaço urbano converge linhas de ação no tempo $\left(T_{1}, T_{2}, T_{3}\right)$ e no espaço $\left(L_{1}, L_{2}, L_{3}, L_{4}\right)$ Fonte: Autores. 
disso, a economia espacial e os estudos urbanos oferecem evidências de que, mesmo complexas, as cidades são lugares ao menos parcialmente estruturados. De padrões de localização descritos desde Alonso (1964) a padrões de acessibilidade descritos de Hansen (1959) a Hillier (1996), sabemos que estruturas urbanas importam: elas implicam que as atividades se materializam de forma reconhecível e acessível. Do ponto de vista da seleção, a percepção de que as atividades são de alguma forma materializadas em uma estrutura espacial é uma forma de pré-seleção. As atividades tendem a ser distribuídas de acordo com níveis de acessibilidade, valores do solo e interdependências, facilitando ações complementares. Mesmo que inconscientemente e sujeito a contingências, o espaço urbano também é estruturado física e informacionalmente, o que permite que possibilidades de ação venham a ser conhecidas (Figura 4). Em um primeiro momento a estrutura urbana suporta uma gama de possibilidades para
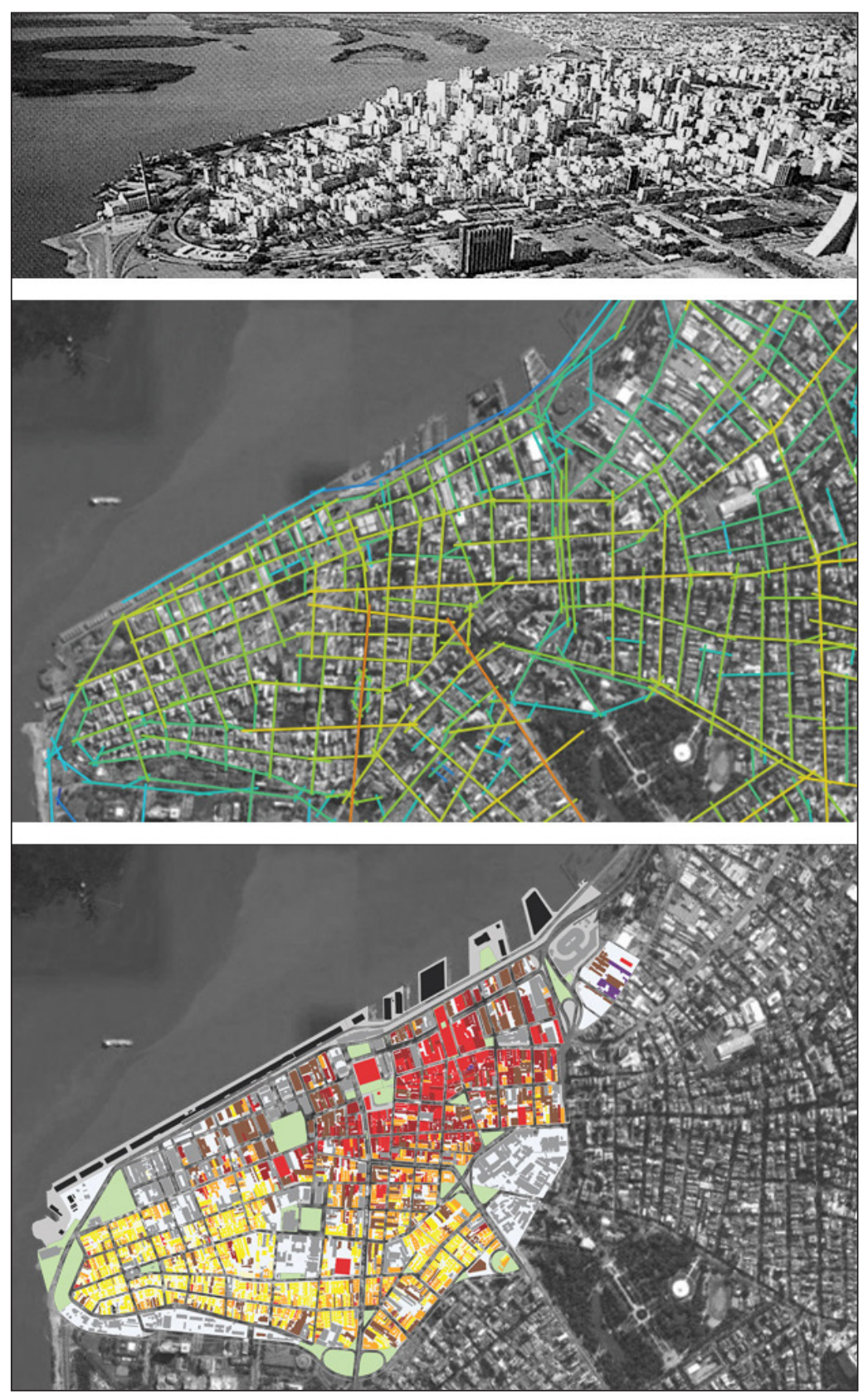

Figura 4 - Padrões de diferenças visuais, configuracionais e de atividades visiveis na cidade de Porto Alegre: 0 espaço como informação à ação Fonte: Google Earth; Maraschin (2014). 
nossa seleção. Em um segundo momento, a estrutura pode sugerir possibilidades atraentes.

Se sistemas sociais são constituídos por conexões entre ações (interações), como nos mostram Parsons (1968) e Luhmann (1995), o espaço pode se tornar parte dessas conexões: parte da transição entre atos individuais e conjuntos de interações: ato individual $\rightarrow$ lugares como conexões $\rightarrow$ sistemas de interação.

Nossa hipótese, a ser examinada nos experimentos na seção seguinte, é que as cidades se tornam uma parte crucial dessa conectividade. Elas ajudariam a reduzir dificuldades como o acesso à informação, riscos de ações inviáveis em termos de tempo, energia ou custos, ou outros riscos que impediriam ações de surgirem espontaneamente (Figura 5).

0 que tudo isso diz sobre o papel das cidades na entropia social? Começando por Luhmann, nossas interações têm um papel estrutural, porque elas representam seleções e colaboram na cooperação e coordenação coletiva das ações. Se relacionarmos isto à entropia de Shannon, veremos que a própria existência de estruturas urbanas elimina cenários onde qualquer interação teria a mesma probabilidade de acontecer. Para entendermos isso, imaginemos novamente uma cidade sem estrutura, completamente homogênea ou completamente heterogênea, sem padrões como centros, áreas mais densas ou ruas mais comerciais. A probabilidade de encontrarmos uma atividade nessa cidade seria distribuída de modo igual no espaço. A atividade que nos interessa poderia estar em qualquer lugar. Isso seria um enorme problema: interações interessantes para a maioria das pessoas seriam tão difíceis de encontrar como qualquer outra. Cidades totalmente homogêneas ou totalmente heterogêneas teriam máxima entropia. Seus ambientes seriam inúteis para facilitar interações - muito diferentes das ruas e áreas reais que concentram atividades de interesse.

Quando o espaço urbano encontra formações diferenciadas - como caminhos mais acessíveis ele naturalmente gera diferenças na probabilidade das interações: certas interações se tornam mais prováveis do que outras. Padrões de localização são na verdade expressões de sistemas de interação. São as diferenças materializadas nesses padrões que aumentam as chances de encontrarmos certo agente ou atividade. Quando essas atividades também estão relacionadas temporalmente, em complementaridades

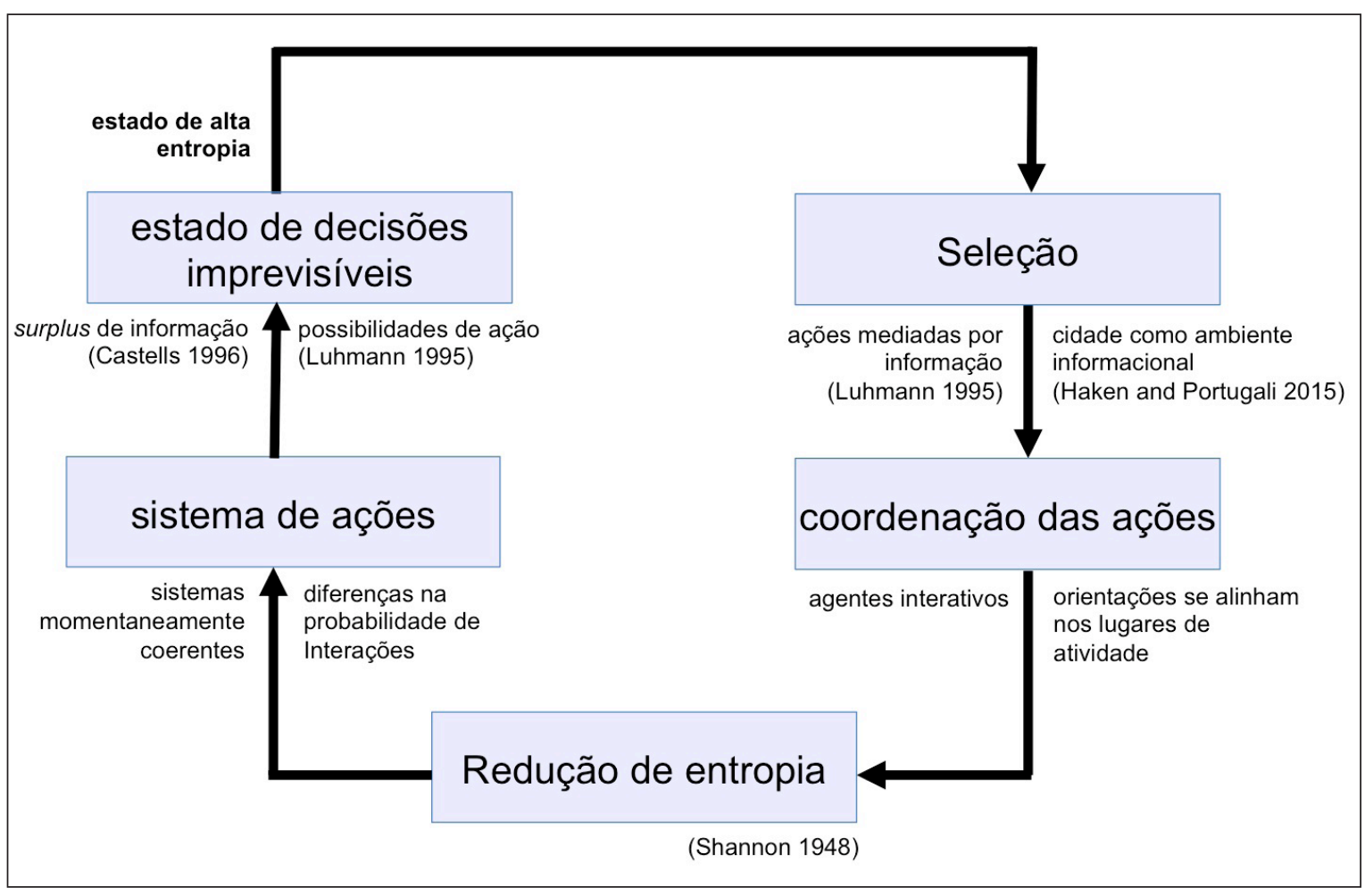

Figura 5 - Um processo recursivo conduz o sistema social de estados caóticos (alta entropia) a sistemas coerentes (baixa entropia) Fonte: Autores. 
funcionais, há um potencial ainda maior para que diferenças de probabilidade emerjam, sugerindo novas interações. $O$ que tudo isso significa é que as cidades, internamente diferenciadas, mas longe da heterogeneidade absoluta ou do caos, são meios para reduzir entropia social.

Linearizando processos que na realidade ocorrem simultaneamente, o efeito do espaço na entropia social seguiria este fluxo (Figura 6):

a. Imagine ações livres de espaço, movendo-se como linhas no tempo. Agentes podem fazer qualquer coisa, e não podemos prever o que eles vão fazer. Esteé um estado de alta entropia. As cores das linhas caóticas na Figura 6 representam diferentes conteúdos nas orientações que norteiam essas ações;

b. Em seguida, os agentes começam a selecionar ações e a convergir em lugares (as cores na faixa vertical na Figura 6) a fim de interagir. As linhas de ação podem ter diferenças sutis em relação aos conteúdos dos lugares, nos quais convergem por proximidade informacional e espacial.
Essas conexões só podem acontecer se todas as outras possibilidades de conexão forem preteridas;

c. Enquanto essas convergências acontecem, a trama inicialmente caótica vai ficando mais e mais ordenada, indo em direção a um sistema coordenado, onde os agentes cooperam. A entropia das ações é reduzida;

d. Após cada atividade social, as ações individuais podem mudar de novo, de acordo com mudanças nas orientações subjetivas. Assim, as cores das linhas de ação mudam. Como as ações entram em novo estado de imprevisibilidade, a entropia volta a aumentar: novas possibilidades se apresentam aos agentes, e algumas delas devem ser selecionadas para que novas ações aconteçam;

e. [...]então, as ações dos agentes voltam novamente a se referir aos significados e lugares no espaço urbano, iniciando um novo ciclo de redução de entropia.

Estes momentos são distintos apenas teoricamente, é claro. Na realidade, lembrando Prigogine \& Stengers (1984), esta "multidão de eventos" ocorre

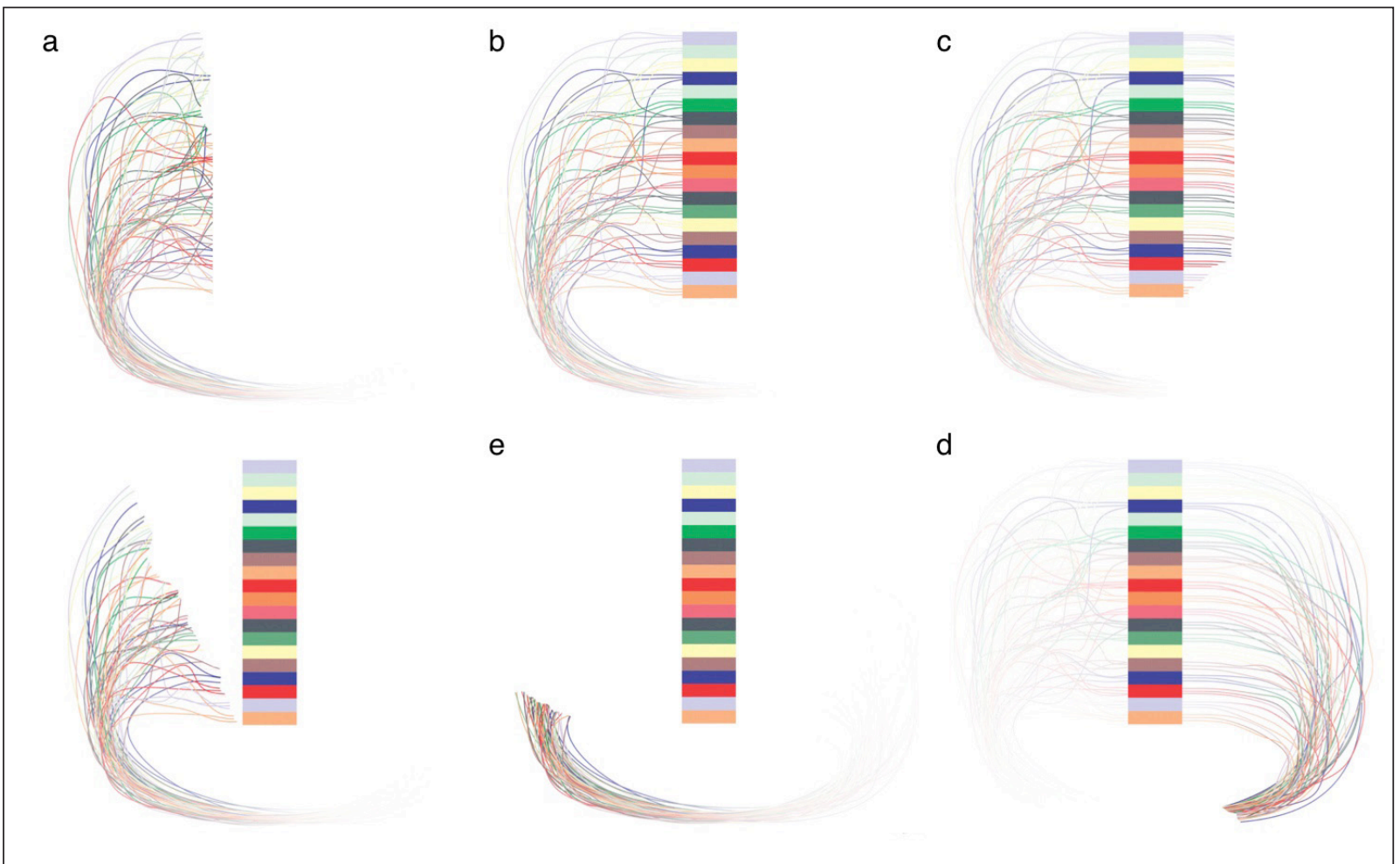

Figura 6 - 0 ciclo de entropia, no sentido horário: da alta imprevisibilidade das aç̃oes a um sistema momentaneamente ordenado, quando aç̦eses convergem em lugares - apenas para merguharem novamente em entropia Fonte: Autores. 
simultaneamente, o que pode tornar qualquer ciclo invisível. Mas isso não significa que ciclos individuais não aconteçam ou sejam agregados, nem que eles sejam anulados entre si. Na verdade, a rotinização da vida diária leva a ritmos e ciclos reconhecíveis, que coexistem e se desdobram a partir de ações aparentemente caóticas. Convergimos para lugares de atividade para atuar com outros, e fazemos isso diariamente. Dentro de um lugar, a interação requer níveis de cooperação. Podemos trazer nossas próprias orientações, sob a forma de memória de longo prazo sobre como atuar, juntamente com a memória de curto prazo de uma ação anterior, ambas moldando nossas ações atuais. Ao agirmos socialmente, colocamos nossas orientações em contato, de forma a abri-las no processo de comunicação. É essa interação que regula a ação coletiva. Um resultado desta coordenação de ações é reduzir as diferenças iniciais entre elas. Nossas ações se alinham dentro de um lugar de atividade (Figura 7).

Mas mesmo se nossas ações tendessem à sincronia, a trama das nossas ações ainda enfrentaria o desafio da entropia: o problema de produzir diferenças de probabilidade nas interações como uma forma de gerar organização social. Isso aconteceria sempre que os agentes se sentem impelidos a novas interações - um processo recorrente. Tudo isso sugere que a reprodução social inclui um tratamento contínuo da entropia - uma oscilação vital entre previsibilidade e imprevisibilidade. Este processo envolve um número enorme de pessoas e eventos. Ele transcende contextos, e até o momento não pode ser observado em seu todo. Infelizmente, pelo que parece, a entropia só pode ser plenamente compreendida via imaginação e representação. Em função dessa dificuldade empírica, um modo de examinar o papel do espaço na entropia é através de simulações - uma forma de gerar um "mundo contrafatual" onde outros meios de coordenação da ação como a linguagem ou regras fossem "desligados", mantendo ativas apenas as propriedades sob investigação - neste caso, o espaço, juntamente com as habilidades dos agentes em atuar e alinhar ações. Uma vez que reconstruamos essas condições abstraindo outros meios, poderemos avaliar se o espaço pode mesmo ter um papel na interação social.

\section{Experimentos digitais: um modelo unidimensional}

Um modelo tem o papel de representar os processos empíricos tidos como mais relevantes com a maior simplicidade possível: ele precisa dizer o máximo com o mínimo de elementos. Para tanto, precisa abstrair heterogeneidades, incluindo diferenças contextuais e culturais, para focar nos processos e componentes mais fundamentais, com maior potencial causal - e sobretudo mais comuns a cidades diferentes (lembrando que a cidade é um fenômeno que atravessa contextos). 0 modelo se concentra nos fatores com repercussões tidas como mais significativas na rede de relações que compõe o fenômeno.

Neste espírito, propomos um modelo baseado em agentes (agent based model, ABM) para testar o papel de fatores sociais e espaciais na organização da ação. Os agentes são caracterizados por seu impulso à ação, e os lugares, por tipos de atividades correspondentes. As ações podem ser influenciadas por condições diferentes, como (i) a orientação latente do agente, representando a tendência de agir em torno de um

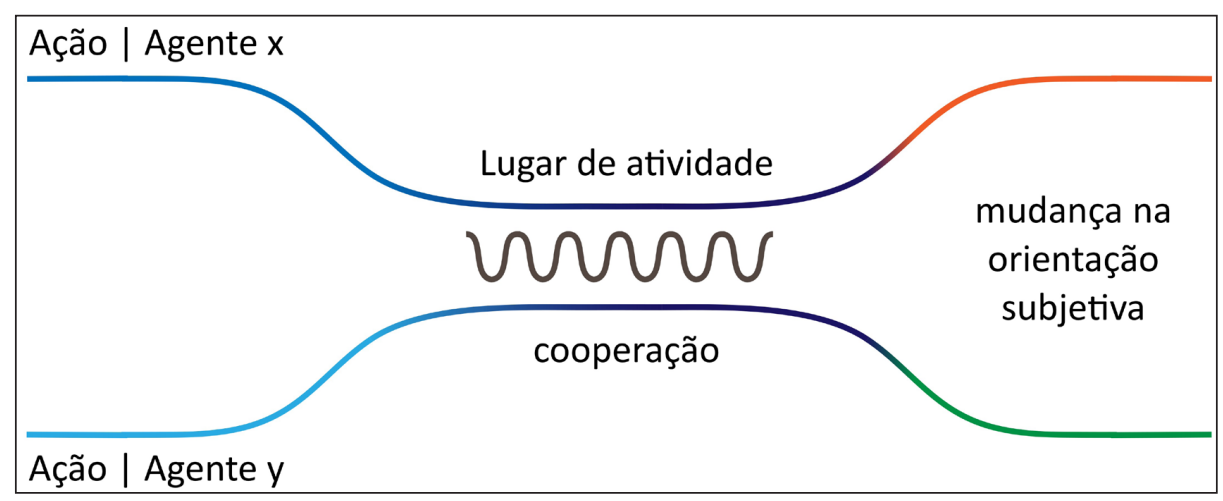

Figura 7 - 0 alinhamento das aç̃oes no processo de cooperação Fonte: Autores. 
tipo particular de ação, inicialmente distribuída aleatoriamente; (ii) a ação atual, representando uma intenção para realizar uma nova ação e selecionar um local de atividade para fazê-lo, e que muda no tempo; e (iii) o lugar de atividade que suporta ações correspondentes. Os agentes seguem regras simples, selecionando lugares de atividade mais próximos a suas orientações latentes e atuais, ao mesmo tempo em que suas orientações atuais também são influenciadas por essas atividades. As atividades também mudam sob a influência das ações dos agentes - mas mais lentamente do que as ações mudam. Em resumo, os agentes se adaptam ao seu ambiente espacial e social (Axelrod, 1997), enquanto seu ambiente espacial e social se adapta a eles. Diferenças no peso desses fatores poderiam ser suficientes para gerar diferentes níveis de entropia, sugerindo itens para a compreensão do fenômeno. Embora haja uma tradição de modelagem de atividades diárias, incluindo dados de localização digital (e.g. Farber et al., 2015), nosso $\mathrm{ABM}$ não visa representar realisticamente sequências empíricas de atividades ou rotinas. Em vez disso, ele se concentra em capturar tendências que podem emergir das interfaces de sistemas simplificados de ação, informação e espaço.

Considere uma cidade unidimensional, formada por agentes e lugares. Lugares formam um anel com o comprimento (ou perímetro) $L$, como vemos na Figura 8. A cidade circular contém duas propriedades

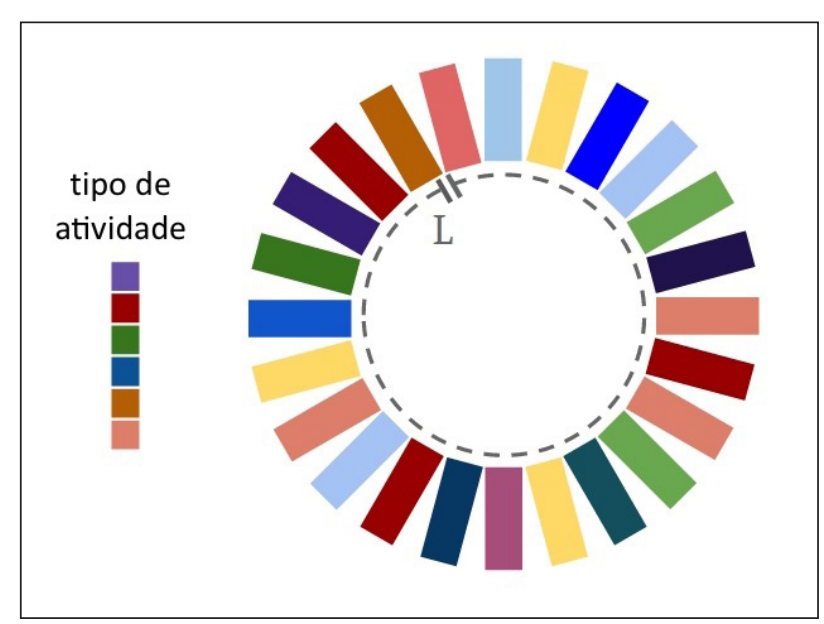

Figura 8 - A cidade teórica unidimensional com um conjunto de lugares de atividade. Temos $L$ edifícios distribuídos em um anel, constituindo 0 espaço da cidade. As cores representam os tipos de atividade Fonte: Autores. comuns em cidades reais e potencialmente de grande repercussão: a diferenciação informacional do espaço (os conteúdos sociais dos edifícios, que são reconhecidos pelos agentes para orientar suas escolhas e ações) e um espaço físico extenso (incluindo distância, modelada em um dos dois cenários a serem examinados). Nossa escolha em representar a cidade por um anel é em função da representação linear mínima e suficiente da distância (como em Schelling, 1971; Krafta et al., 2011; Lanchier \& Scarlatos, 2013). A forma do anel permite o movimento contínuo dos agentes em uma sequência de lugares, eliminando fatores de centralidade, efeitos de borda e o papel da topologia, enquanto isolamos o problema da distância (Ribeiro \& Ribeiro, 2015). Portanto, esta cidade simulada permite examinar os efeitos da distância e da diferenciação dos lugares. Ela é composta por $N$ agentes, que selecionam e visitam um lugar específico localizado na posição $x$ na cidade em cada passo de tempo $t$. Considere que a posição do $i$-ésimo agente no tempo $t$ é representado por $x_{i}(t)$. A posição de um agente pode assumir valores inteiros $1,2, \ldots L$, de acordo com o lugar que ele escolhe para visitar.

Consideremos $\sigma_{i}(t)$ como a orientação da ação do $i$-ésimo agente e $\sigma_{x}(t)$ a atividade realizada em um lugar situado na posição $x=(1,2, \ldots L)$ da cidade, no tempo $t$. Vamos assumir que a orientação é um número inteiro entre zero e 1.000, que cada número representa um tipo específico de orientação, e que os números nas suas imediações significam orientações semelhantes. Então, há duas orientações de ação extrema: $\sigma=0$ e $\sigma=1.000$. A diferença $\left|\sigma_{i}(t)-\sigma_{x}(t)\right|$ nos dá a diferença de orientação entre um agente e a atividade de um lugar.

Um agente escolhe um lugar específico com base na sua afinidade de orientação com este lugar. Como diz a hipótese central acima, a estrutura urbana pode ter um papel neste processo de seleção. Neste experimento, reduzimos "estrutura urbana" à distância. A fim de investigar como a distância pode ou não interferir na seleção, propusemos dois cenários. No primeiro, o agente seleciona um lugar específico com base apenas na similaridade em orientações entre ele e o lugar de atividade. $O$ agente pode se mover livre de fricção, e o espaço não é uma restrição ao movimento. No segundo cenário, mais realista, o espaço gera fricção ao movimento. 0 agente precisa levar em conta a distância entre a sua posição original na cidade e as posições dos lugares, e opta por minimizar essa 
distância. Este cenário considera o parâmetro $E_{i}(x, t)$ que fornece informações sobre a interação entre o agente $i$ e o lugar localizado em $x$ no momento $t$. 0 agente seleciona lugares de atividade que minimizam esta quantidade.

No primeiro cenário, que considera apenas as diferenças na orientação, propomos a Equação 1:

$E_{i}(x, t)=\left|\sigma_{i}(t)-\sigma_{x}(t)\right|$.

No segundo cenário, que também considera a distância entre a posição atual de um agente e o lugar da sua próxima atividade, propomos a Equação 2:

$E_{i}(x, t)=\left|\left(x_{i}(t)-x\right)\right|\left|\sigma_{i}(t)-\sigma_{x}\right|$.

Resumindo, um agente $i$ seleciona no tempo $t$ um lugar para realizar uma atividade, que por sua vez está localizada em $x$, e que minimiza a função $E_{i}(x, t)$.

\section{A evolução das orientações da ação}

Quando um agente escolhe e vai a um lugar particular, ambos agente e lugar se tornam um pouco mais parecidos em termos de orientação. Isso significa que os lugares não são imunes ao que os agentes fazem neles, e que o sistema de atividade também muda com o tempo. Para ilustrar como as orientações são constantemente atualizadas, consideremos que agente $i$ seleciona um lugar de atividade localizado em $x^{\prime}$. A orientação será atualizada de acordo a Equação 3:

$$
\sigma_{i}(t+1)=\frac{1}{\propto+\beta+\gamma}\left(\propto \sigma_{i}^{i n}+\beta \sigma_{i}(t)+\gamma \sigma_{x^{\prime}}(t)\right)
$$

A seleção depende de três parâmetros: a orientação latente, ponderada pelo parâmetro $\alpha$; a ação atual, ponderada pelo parâmetro $\beta$; e o lugar de atividade, ponderado pelo parâmetro $\gamma$.

A orientação latente se refere a uma tendência de comportamento que chamamos $\sigma_{i}^{O}$. Em nossos experimentos, consideramos que as ações acontecendo no tempo $\sigma_{i}{ }^{I N}(t)$ têm uma distribuição normal em torno de $\sigma_{i}^{o}$. Se $\alpha$ é suficientemente pequeno em relação a $\beta$ e $\gamma$, então a orientação latente não desempenha papel na ação. No entanto, se $\alpha$ é suficientemente grande (em relação a $\beta$ e $\gamma$ ), a ação torna-se fortemente dependente da orientação latente.
A ação atual pode influenciar uma nova ação com uma intensidade que depende do parâmetro $\beta$. Se este parâmetro é pequeno (em comparação com $\alpha$ e $\gamma$ ), o agente não guarda memória da ação atual na sua próxima seleção. No entanto, se $\beta$ é suficientemente grande (em relação aos outros parâmetros), então o agente é fortemente dependente da sua ação recente (um comportamento Markoviano).

A intensidade da influência do lugar de atividade sobre a ação depende do valor de $\gamma$. Se este parâmetro é pequeno (em comparação a $\alpha$ e $\beta$ ), a atividade não afeta a ação. No entanto, se este parâmetro é suficientemente grande (em relação aos outros parâmetros), então o lugar desempenha uma forte influência sobre a nova ação. 0 lugar de atividade será atualizado de acordo a regra da Equação 4:

$\sigma_{x^{\prime}}(t+1)=\sigma_{x^{\prime}}(t)+\theta \sum_{i \in x^{\prime}} \sigma_{i}(t)$,

em que $\theta$ é um parâmetro suficientemente pequeno. Ou seja, os lugares são menos influenciados por agentes do que o contrário. Isso significa que a cada passo de tempo, um lugar teria seu tipo de atividade um pouco mais próximo da média de orientações de seus visitantes.

A frequência de orientações e níveis de entropia

Considere $N(\sigma, t)$ como o número de agentes com orientação $\sigma$ no tempo $t$. A população total é $N=\sum_{\sigma} N(\sigma, t)$. Podemos calcular a frequência (ou densidade) da orientação $\rho(\sigma, t)$ no tempo (Equação 5):

$\rho(\sigma, t)=\frac{1}{N} N(\sigma, t)$

Também podemos calcular o nível de entropia para qualquer distribuição de orientações com a Equação 6:

$S(t)=-\sum_{\sigma} \rho(\sigma, t) \ln (\rho(\sigma, t))$

A redução da entropia implica que a probabilidade de certas ações aumenta, ou seja, certas ações vão convergindo em similaridade. No limite, quando 
a entropia cai a zero, todos os agentes do sistema atingiriam a mesma orientação.

\section{Procedimentos do modelo}

O modelo executa os seguintes procedimentos:

(a) A cidade é criada através da geração de dois itens:

(a.1) a posição inicial dos $N$ agentes, que é $\left(x_{1}, x_{2}, \ldots, x_{N}\right)$, com as suas respectivas orientações $\left(\sigma_{1}(t=0), \sigma_{2}(t=0), \ldots, \sigma_{N}(t=0)\right)$, geradas a partir de uma distribuição aleatória;

(a.2) o tipo de atividades dos lugares, isto é $\left(\sigma_{x=1}(t=0), \sigma_{x=2}(t=0), \ldots, \sigma_{x=L}(t=0)\right)$, também gerado a partir de uma distribuição aleatória.

(b) A cada passo de tempo $t$ cada agente escolhe um lugar para atuar. Este lugar é aquele que minimiza a função potencial $E_{i}(x, t)$. Assuma que o lugar escolhido por um agente é definido por $x$ ' Então agente e lugar atualizam suas orientações $\sigma_{i}$ e $\sigma_{x^{\prime \prime}}$ respectivamente;

(c) 0 modelo atualiza a distribuição de orientações $\rho(\sigma, t)$;

(d) 0 modelo computa a entropia de Shannon $S(t)$.
Resultados

Desenvolvemos um número de observações sobre o comportamento de sistemas socioespaciais sob diferentes parâmetros.

- A redução de entropia só é encontrada em cenários onde o espaço impõe atrito ao movimento, ou seja, onde a distância entre agentes e lugares é considerada como um fator ativo na seleção. De acordo com o modelo, a entropia precisa do espaço para ser reduzida. Mas o espaço não pode fazer isso sozinho. $O$ espaço é uma condição necessária, mas não suficiente. A Figura 9 compara dois cenários. No primeiro deles, a distância é um problema na seleção de atividades (linha vermelha). A distribuição das orientações muda de uma distribuição homogênea no início da simulação (esquerda) para uma distribuição quase normal no final (à direita), na qual certos tipos de ação são mais prováveis. Conteúdos informacionais no espaço ajudam a alinhar as ações. No segundo cenário, os agentes se movem livres de atrito espacial (linha azul). As orientações são inicialmente distribuídas aleatoriamente (esquerda) e continuam assim no final da simulação (à direita), dado que um número similar de agentes está distribuído ao longo de diversas orientações. Este resultado sugere que o espaço materialmente ativo se

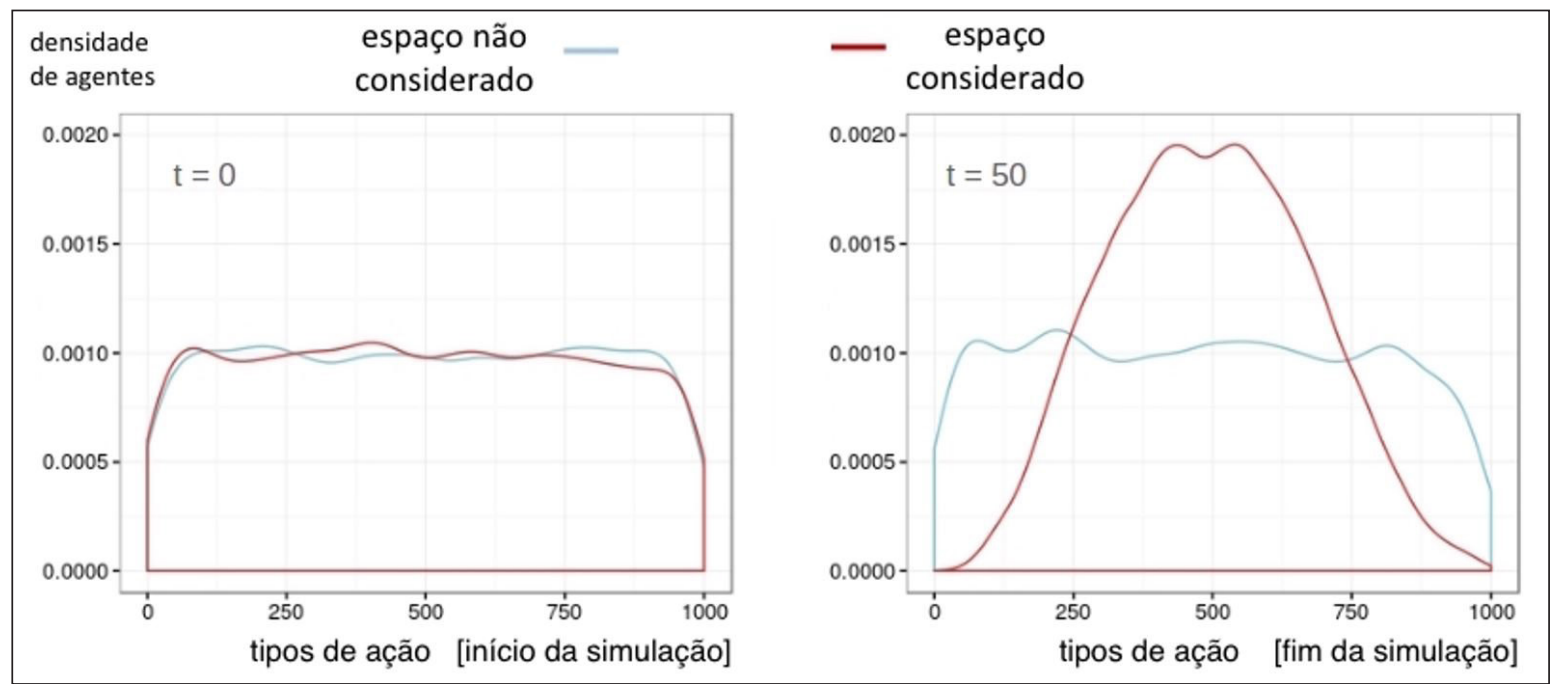

Figura 9 - Densidade de tipos de ação no início (à esquerda) e no final (à direita) das simulações no cenário em que a distância não é considerada (azul) e em que a distância é considerada (vermelho). Os resultados são médias de 30 rodadas de simulação para cada uma das 125 combinaç̃̃es de parâmetros Fonte: Autores. 
torna um meio para aumentar a probabilidade de certas interações, facilitando a coordenação da ação coletiva.

Avaliando a influência da informação em lugares de atividade, da orientação latente e da ação atual sobre a próxima ação, sob influência da distância (Figura 10), podemos dizer que:

- Há estrutura na relação entre fatores de seleção e a redução da entropia. A dinâmica começa com queda, para em seguida oscilar em torno de valores específicos, de acordo com diferentes combinações de fatores. Para algumas combinações, há uma grande redução de entropia. Para outras, a redução é mínima, quase insignificante;

- Uma forte orientação latente ( $\alpha$ suficientemente grande) leva a um aumento da entropia (linhas azuis nas Figuras 10 e 11), uma vez que os agentes não têm abertura suficiente para alinhar suas ações com as ações de outros agentes. Como uma memória de longo prazo, os sistemas onde as

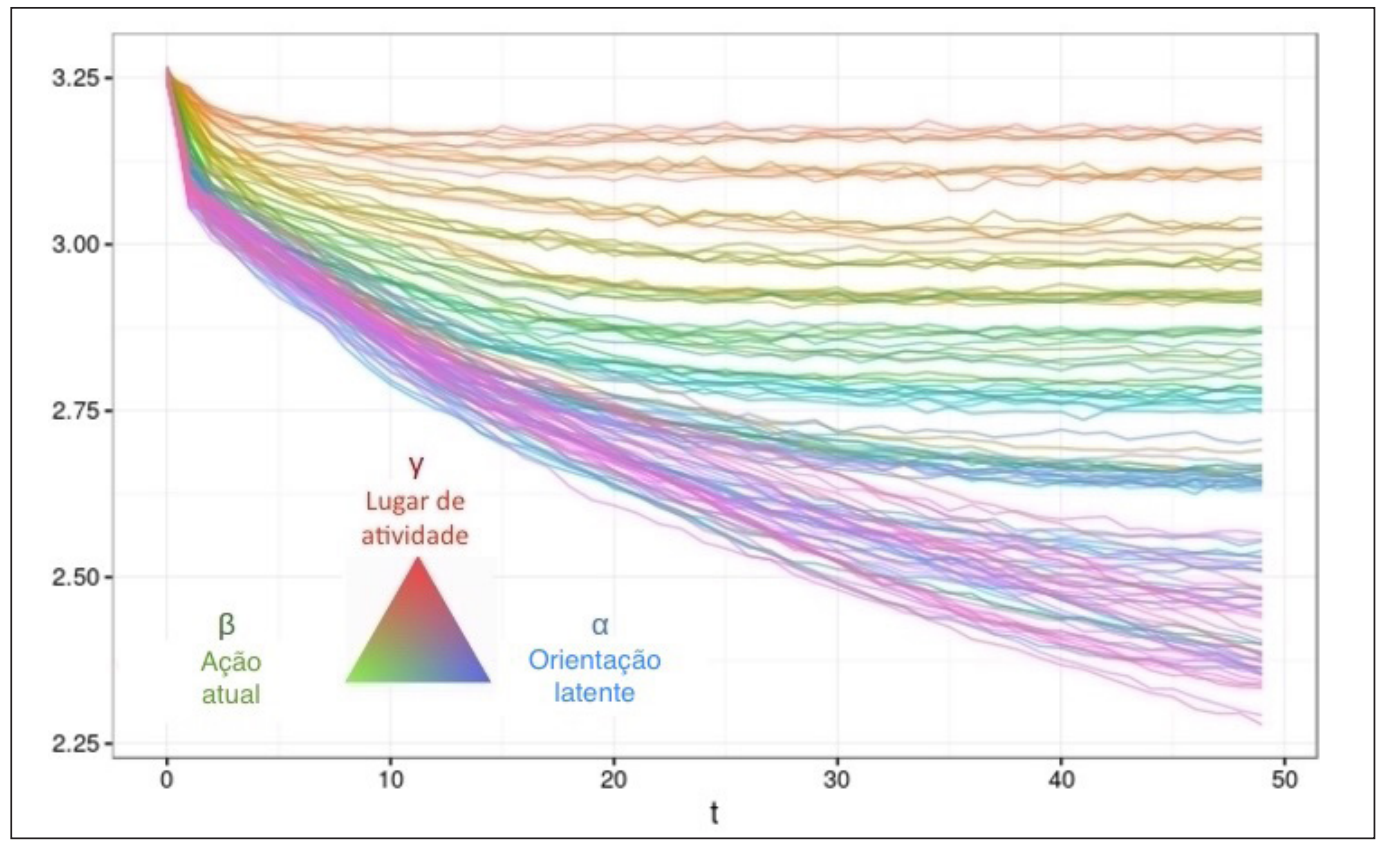

Figura 10 - Evoluç̦ão de entropia: as cores em escalas RGB se referem ao papel dos parâmetros nas decisões sobre ações a serem executadas em um intervalo de tempo e seu impacto sobre os níveis de entropia em diferentes simulações (sob a fricção da distância). № triângulo, cada cor representa uma combinaçãa especíica dos três parâmetros. Em cada vértice, um parâmetro atinge 0 valor máximo enquanto os outros têm valor mínimo. Os resultados são médias de 30 rodadas de simulação para cada uma das 125 combinaç̃oes de parâmetros Fonte: Autores.
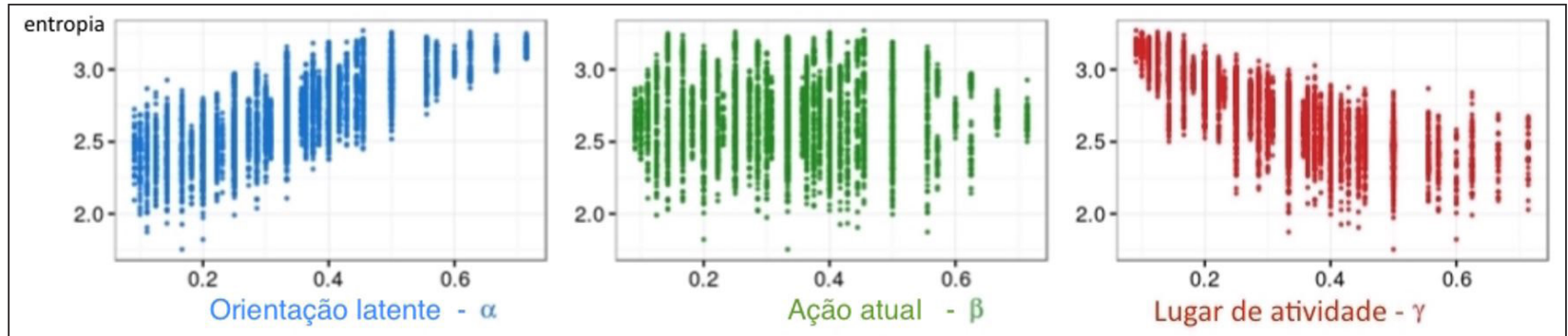

Figura 11 - Exploração de parâmetros: vemos aqui a importância de cada parâmetro isolado na entropia (sob a fricção da distância). Cada conjunto de pontos verticais representa um valor fixo para o parâmetro, com os dois outros parâmetros assumindo todas as combinações possíveis dentro da gama testada. Cada ponto corresponde ao valor de entropia quando um tempo suficientemente grande transcorre Fonte: Autores. 
ações são ditadas por orientações latentes tendem a preservar suas orientações iniciais, distribuídas aleatoriamente. A influência da ação atual sobre uma nova ação não a molda de modo específico (linhas verdes nas Figuras 10 e 11). Ela apenas estimula a repetição do que já está acontecendo, funcionando como um "feedback de reforço" para a direção em que o agente e o sistema estão indo;

- Os lugares de atividade têm um papel fundamental na redução da entropia (linhas vermelhas nas Figuras 10 e 11). As informações sociais no espaço "contaminam" os agentes: eles alinham suas ações através dos conteúdos sociais dos lugares e edifícios. Testes com o cenário livre de fricção da distância mostraram que o espaço importa enquanto extensão. Agora vemos que a informação no espaço também tem um papel ativo na organização social;

- A combinação de fatores tem efeito: a conjunção de orientações influenciadas pelas atividades e por orientação latente leva à redução mais forte da entropia (linhas cor de rosa na Figura 10). Isso significa que quando os agentes não mantêm informações sobre suas seleções recentes ( $\beta$ muito pequeno), o sistema se organiza mais intensamente do que em outras configurações;

- Finalmente, a redução de entropia implica que a probabilidade de certas ações aumenta. Isto significa mais alinhamento entre agentes, e mais conexões entre suas ações (isto é, mais interações). No entanto, se todos os agentes atingirem a mesma orientação, a entropia cairá para zero e o sistema perderá diferenciação interna. Os agentes se comportariam de uma mesma maneira, em um mundo sem diferenciação pessoal, especialização. Novas orientações (portanto, mais entropia) são necessárias se o sistema social pretende manter suas agências diferenciadas entre si ou uma divisão do trabalho. Por outro lado, um sistema com máxima entropia geraria diferença de ações a um ponto onde nenhuma coordenação entre ações seria possível. Esta situação tampouco pode ser o caso. A reprodução de um sistema social envolve nem total entropia, nem total previsibilidade.
Esses resultados também sugerem que estamos lidando com o papel de "memórias sociais" distintas: a memória de longo prazo estaria ativa no que chamamos de orientações latentes. A memória de curto prazo estaria ativa na influência das orientações atuais sobre as futuras ações. Por sua vez, as informações sociais latentes nos lugares de atividade são arranjos sociais (na forma de instituições, comércios, uma economia local) que mudam muito mais lentamente do que as ações. É uma extensão do sistema social projetada no espaço urbano.

\section{Cidade e interação: conclusões}

O que esta abordagem traz para o estado da arte sobre as relações entre interação, informação e espaço, e sobre entropia em particular? Vimos que abordagens anteriores à entropia social tendem a subestimar a coordenação da ação como problema central. Além disso, elas tendem a ter uma espacialidade frágil (e.g. Bailey, 1983, 2006). Por sua vez, embora o conceito de "ação coletiva" esteja finalmente recebendo atenção em estudos urbanos (e.g. Batty, 2013), o problema é ainda bastante subestimado. Abordagens à entropia são raras, e lidam principalmente com a forma urbana (Haken \& Portugali, 2015) e distribuição espacial (Batty et al., 2014), e não com informação útil à ação social. Como autores, tampouco temos conhecimento de uma teoria ou modelo que lide com o problema de como as cidades e o espaço urbano são parte da interação como problema de organização e reprodução social.

Até que ponto o modelo corrobora a teoria? Um modelo tem o papel de recriar as relações entre os fatores reconhecidos pela teoria (orientações, ações, espaço informacional, distância) e verificar se ela faz sentido. Nosso modelo não traz uma demonstração empírica, mas uma "prova do conceito" capaz de demonstrar a viabilidade da teoria. Como o problema da entropia tem limitada possibilidade de verificação empírica, o experimento computacional é uma forma de investigar seus modos de existência e como o espaço seria parte deles. Um resultado que esperávamos do nosso modelo é que o espaço faria diferença na coordenação das interações - mas foi surpreendente ver que o espaço como extensão apareceu como uma condição necessária, mas não suficiente para a redução da entropia. Isso sugere que a materialidade física não 
é o bastante. Sugere uma presença causal do espaço físico, mas não determinística. A informação social lida nos lugares e a história pessoal dos agentes também se mostraram importantes na coordenação da ação. O modelo é capaz de identificar papéis para a cognição e a memória nos modos como agentes escolhem ações e lugares de atividade, com consequências sobre a entropia. Todos esses fatores sugerem que o comportamento do modelo não pode ser previsto a partir do comportamento de fatores individuais, algo fundamental no tratamento de fenômenos complexos.

Esta abordagem mostra uma presença das cidades na organização social. Levando em conta critérios simples como a distância como fator de seleção, o modelo mostrou que o espaço se torna um meio para diferenciar probabilidades de ações, aumentando as chances de certas seleções, e de convergências na ação coletiva. Na realidade, lemos diferenças entre lugares de atividade. Um dos pontos centrais do nosso argumento é que essas diferenças nos ajudam a fazer seleções. Cada vez que nos movemos na cidade para fazer nossas coisas, estamos participando nesta coordenação coletiva e inconsciente da ação. Atuamos no espaço urbano como um sistema de significados - um conjunto de bits semânticos indexando atividades, informando e orientando nossas decisões diárias. 0 espaço se torna parte da passagem de orientações a interações reais, gerando amarração entre eventos, re/criando sucessivamente o sistema social. E é por meio de espaços que restringem as possibilidades combinatórias quase infinitas de interação que este sistema pode adquirir coerência interna suficiente para tornar a sua própria reprodução possível.

Uma qualidade desejável de um modelo pode ser também uma limitação. Nossa representação minimalista da cidade, mantendo apenas a distância e os conteúdos informacionais do espaço como ativos na ação, é certamente o caso. Mas embora tenhamos proposto um modelo unidimensional, o comportamento dos agentes pode ser explorado em representações mais realistas, testando os papéis da densidade, configuração e diversidade. Por exemplo, se a distância física importa, como o tamanho e as estruturas internas das cidades afetariam a entropia? E as áreas naturais, rurais ou os subúrbios rarefeitos? Como nosso modelo explora uma cidade circular, ele só começa a responder a tais questões. Nossos achados indicam que distâncias mais curtas entre lugares tendem a reduzir a entropia social. A densidade parece ser importante: as espacialidades mais densas (em oposição às rarefeitas) têm um papel a desempenhar. A passagem da complexidade não estruturada para estruturada pode ser influenciada pelo tamanho e densidade, um assunto recentemente analisado por Batty et al. (2014). Talvez cidades mais densas e estruturadas possam criar, processar e converter informação e entropia em organização com mais intensidade. Um modelo mais realista pode testar esses fatores e adicionar novos aspectos à teoria. Por outro lado, perde a elegância da descrição de um fenômeno complexo a partir de elementos mínimos. Esse desenvolvimento, de qualquer forma, está no horizonte deste trabalho.

Devemos concluir que a entropia é um problema para uma sociedade? Nossa abordagem sugere que não. A entropia deve ser vista como uma força necessária na vida social. Ela significa que novas ações estão entrando no sistema de interações. A entropia só se torna um problema se não for convertida em organização - isto é, se o imenso leque de ações potenciais não for convertido em interações reais. Em geral, os efeitos das novas ações sobre a entropia social são positivos, tendo a ver com a diversidade. Sistemas conservadores têm menos entropia - mas também produzem menos novidades, tendo a homogeneidade como um horizonte problemático. Flutuações de entropia parecem vitais para sociedades complexas.

Finalmente, a nossa intenção foi a de explorar a entropia como um meio para pensar a interação social "de outro ângulo", por assim dizer: a partir do ponto de vista dos desafios envolvidos na reprodução social. Por isso, escolhemos uma abordagem centrada nas incertezas que pessoas enfrentam quando lidam com decisões, e as diferentes probabilidades de ação que se seguem - reunindo teoria social, teorias da informação e cognição e teoria urbana em uma única abordagem. Essa abordagem vê cidades como sistemas de referências cruciais para a ação coletiva. Também sugere que os estados da entropia revelam profundas ligações entre interação, informação e espaço.

\section{Referências}

Alonso, W. (1964). Location and land use: toward a general theory of land rent. Cambridge: Harvard University Press. http://dx.doi.org/10.4159/harvard.9780674730854. 
Axelrod, R. (1997). The dissemination of culture: a model with local convergence and global polarization. The Journal of Conflict Resolution, 41(2), 203-226. http://dx.doi.org/ $10.1177 / 0022002797041002001$.

Batty, M. (2013). The new science of cities. Cambridge: The MIT Press.

Batty, M., Morphet, R., Masucci, P., \& Stanilov, K. (2014). Entropy, complexity, and spatial information. Journal of Geographical Systems, 16(4), 363-385. PMid:25309123. http://dx.doi.org/10.1007/s10109-014-0202-2.

Bailey, K. D. (1983). Sociological entropy theory: toward a statistical and verbal congruence. Quality \& Quantity, 18(1), 113-133. http://dx.doi.org/10.1007/BF00221453.

Bailey, K. D. (2006). Sociocybernetics and social entropy theory. Kybernetes, 35(3/4), 375-384. http://dx.doi. org/10.1108/03684920610653683.

Boltzmann, L. (2015). On the relationship between the second fundamental theorem of the mechanical theory of heat and probability calculations regarding the conditions for thermal equilibrium. Entropy, 17, 1971-2009. http:// dx.doi.org/10.3390/e17041971.

Brooks, R. (1999). Cambrian intelligence: the early history of the new AI. Cambridge: MIT Press.

Buckley, W. (1967). Sociology and modern systems theory. Englewood Cliffs: Prentice-Hall.

Charvat, F. (1972). On philosophical aspects of the system conception in contemporary sociological knowledge. Quality \& Quantity, 6, 3-16. http://dx.doi.org/10.1007/ BF00399169.

Charvát, R., Kucera, J., \& Soukup, M. (1973). Toward the system theory of dependence: further general theoretical remarks. Quality \& Quantity, 7(1), 69-90. http://dx.doi. org/10.1007/BF00172369.

Clark, A. (1997). Being there: putting brain, body, and world together again. Cambridge: MIT Press.

Clark, A., \& Chalmers, D. (1998). The extended mind. Analysis, 58(1), 7-19. http://dx.doi.org/10.1093/analys/58.1.7.

Farber, S., O'Kelly, M., Miller, H. J., \& Neutens, T. (2015). Measuring segregation using patterns of daily travel behavior: a social interaction based model of exposure. Journal of Transport Geography, 49, 26-38. http://dx.doi. org/10.1016/j.jtrangeo.2015.10.009.
Faria, A., \& Krafta, R. (2003). Representing urban cognitive structure through spatial differentiation. In Proceedings of 4th Space Syntax International Symposium (pp. 531-518). London: UCL Press.

Franklin, S. (1995). Artificial minds. Cambridge: MIT Press.

Galtung, J. (1975). Entropy and the general theory of Peace. In J. Galtung (Ed.), Essays in peace research (Vol. L, pp. 47-75). Atlantic Highlands: Humanities Press.

Garfinkel, H. (1967) Studies in ethnomethodolgy. New Jersey: Prentice-Hall.

Gibson, J. (1979). The ecological approach to visual perception. Boston: Houghton-Mifflin.

Glenberg, A. M., \& Robertson, D. A. (1999). Indexical understanding of instructions. Discourse Processes, 28(1), 1-26. http://dx.doi.org/10.1080/01638539909545067.

Goffman, E. (1956). The presentation of self in everyday life. Edinburgh: University Press.

Haken, H., \& Portugali, J. (2015). Information adaptation: the interplay between shannon information and semantic information in cognition. New York: Springer.

Hansen, W. G. (1959). How accessibility shapes land use. Journal of the American Institute of Planners, 25(2), 73-76. http://dx.doi.org/10.1080/01944365908978307.

Heidegger, M. (1962) Being and time. New York: Harper \& Row.

Helbing, D. (2016). The automation of society is next. Zurich: E. T. H.

Hidalgo, C. (2015). Why information grows. Zurich: E. T. H.

Hillier, B. (1996). Space is the machine. Cambridge: Cambridge University Press.

Horan, P. M. (1975). Information-theoretic measures and the analysis of social structures. Sociological Methods \& Research, 3(3), 321-340. http://dx.doi.org/10.1177/004 912417500300305 .

Kintsch, W. (1970) Memory and cognition. New York: John Wiley \& Sons.

Kirsh, D., \& Maglio, P. (1994). On distinguishing epistemic from pragmatic action. Cognitive Science, 18(4), 513-549. http://dx.doi.org/10.1207/s15516709cog1804_1. 
Klapp, O. E. (1975). Opening and closing in open systems. Behavioral Science, 20(4), 251-257. http://dx.doi.org/10.1002/ bs.3830200406.

Kosslyn, S. M. (1994). Image and brain: the resolution of the imagery debate. Cambridge: MIT Press.

Krafta, R., Netto, V. M., \& Lima, L. (2011). Urban built form grows critical. Cybergeo: European Journal of Geography, $565,11-26$

Lakoff, G., \& Johnson, M. (1999). Philosophy in the flesh: the embodied mind and its challenge to Western thought. New York: Basic Books.

Lanchier, N., \& Scarlatos, S. (2013). Fixation in the onedimensional Axelrod model. Annals of Applied Probability, 23(6), 2538-2559. http://dx.doi.org/10.1214/12-AAP910.

Luhmann, N. (1995). Social systems. Stanford: University Press.

Maraschin, C. (2014). Dinâmica e resiliência das áreas comerciais: uma abordagem configuracional em Porto Alegre, $R S$. Porto Alegre: UFRGS, PROPUR. Projeto de Pesquisa.

McFarland, D. D. (1969). Measuring the permeability of occupational structures; an information-theoretic approach. American Journal of Sociology, 75(1), 41-61. http://dx.doi. org/10.1086/224744

Michaelian, K., \& Sutton, J. (2013). Distributed cognition and memory research: History and future directions. Review of Philosophy and Psychology, 4(1), 1-24. http:// dx.doi.org/10.1007/s13164-013-0131-x.

Mills, C. W. (1959). The sociological imagination. New York: Oxford University Press.

Miller, J. G. (1978). Living systems. New York: McGraw-Hill.

Netto, V. M. (2008). Practice, space, and the duality of meaning. Environment and Planning. D, Society \& Space, 26(2), 359-379. http://dx.doi.org/10.1068/d0406.

Netto, V. M. (2017). The social fabric of cities. New York: Routledge.

Neisser, U. (1994). Multiple systems: a new approach to cognitive theory. The European Journal of Cognitive Psychology, 6(3), 225-241. http://dx.doi.org/10.1080/09541449408520146.
Parsons, T. (1968). The structure of social action. New York: The Free Press.

Parsons, T. (1972) The system of modern societies. New Jersey: Prentice-Hall.

Passini, R. (1992). Wayfinding in architecture. New York: Van Nostrand Reinhold.

Pfeifer, R., \& Scheier, C. (1999). Understanding intelligence. Cambridge: MIT Press.

Portugali, J. (2011). Complexity, cognition and the city. New York: Springer. http://dx.doi.org/10.1007/978-3-642-19451-1.

Prigogine, I., \& Stengers, I. (1984). Order out of chaos: man's new dialogue with nature. New York: Bantam Books.

Rapoport, A. (1982). The meaning of the built environment. London: Sage.

Ribeiro, F. L., \& Ribeiro, K. N. (2015). A one dimensional model of population growth. Physica A, 434, 201-210. http://dx.doi.org/10.1016/j.physa.2015.03.021.

Rosch, E. (1978). Principles of categorization. In E. Rosch, \& B. Lloyd (Eds.) Cognition and categorization. Hillsdale: Lawrence Erlbaum.

Schelling, T. C. (1971). Dynamic models of segregation. The Journal of Mathematical Sociology, 1(2), 143-186. http:// dx.doi.org/10.1080/0022250X.1971.9989794.

Shannon, C. E. (1948). A mathematical theory of communication. The Bell System Technical Journal, 27(4), 623-656. http:// dx.doi.org/10.1002/j.1538-7305.1948.tb00917.x.

Vygotsky, L. (1978). Vygotsky, mind in society: the development of higher psychological processes. Cambridge: Harvard University Press.

Weber, M. (1978). Economy and society (Vol. 1). Berkeley: University of California Press.

Wilson, M. (2002). Six views of embodied cognition. Psychonomic Bulletin \& Review, 9(4), 625-636. PMid:12613670. http://dx.doi.org/10.3758/BF03196322.

Wittgenstein, L. (2001). Philosophical investigations. London: Blackwell.

Recebido: Abr. 11, 2017

Aprovado: Ago. 28, 2017 